\title{
Design and Performance of the Sorbent-Based Atmosphere Revitalization System for Orion
}

\author{
James A. Ritter, Steven P. Reynolds, and Armin D. Ebner \\ Department of Chemical Engineering, University of South Carolina \\ Columbia, SC, USA \\ James C. Knox \\ Marshall Space Flight Center, National Aeronautics and Space Administration \\ Huntsville, AL, USA \\ M. Douglas LeVan \\ Department of Chemical Engineering, Vanderbilt University \\ Nashville, TN, USA
}

\begin{abstract}
Validation and simulations of a real-time dynamic cabin model were conducted on the sorbentbased atmosphere revitalization system for Orion. The dynamic cabin model, which updates the concentration of $\mathrm{H}_{2} \mathrm{O}$ and $\mathrm{CO}_{2}$ every second during the simulation, was able to predict the steady state model values for $\mathrm{H}_{2} \mathrm{O}$ and $\mathrm{CO}_{2}$ for long periods of steady metabolic production for a 4-person crew. It also showed similar trends for the exercise periods, where there were quick changes in production rates. Once validated, the cabin model was used to determine the effects of feed flow rate, cabin volume and column volume. A higher feed flow rate reduced the cabin concentrations only slightly over the base case, a larger cabin volume was able to reduce the cabin concentrations even further, and the lower column volume led to much higher cabin concentrations. Finally, the cabin model was used to determine the effect of the amount of silica gel in the column. As the amount increased, the cabin concentration of $\mathrm{H}_{2} \mathrm{O}$ decreased, but the cabin concentration of $\mathrm{CO}_{2}$ increased.
\end{abstract}

\section{INTRODUCTION}

Recent advances [1-7] in cyclic adsorption process modeling have revived the interests of NASA to assist them in the design and development of the next generation sorbent-based atmosphere revitalization (SBAR) system for water $\left(\mathrm{H}_{2} \mathrm{O}\right)$ and carbon dioxide $\left(\mathrm{CO}_{2}\right)$ removal from spacecraft cabins. However, there are fundamental differences between Earth-bound and spacecraft cyclic adsorption processes. These subtle differences present some interesting challenges to the design of an SBAR system.

In space, vacuum is readily available. So, it is used to lower the partial pressures of the adsorbates in the bed to desorb them from a nearly saturated adsorbent. In contrast, on Earth dilutant gases are cheap. So, they are generally used as purge, which also effectively lowers the partial pressures of the adsorbates in the bed to desorb them. Although a dilutant gas can certainly be used in spacecraft applications, the need for a continuous supply of it would be exorbitantly expensive. As a result, the development of cyclic adsorption processes for commercial and spacecraft needs has followed different paths, with extremely large pressure ratios generally replacing relatively high purge flows to foster bed regeneration. Finally, weight on the spacecraft is a critical issue. To reduce weight, a layered bed configuration is necessary.

The concept of a layered bed for a cyclic adsorption process is not new. A layered bed becomes of interest when components of very different adsorptivity need to be adsorbed from a feed stream [8]. The basic principle is to use a weak adsorbent at the inlet followed by stronger adsorbents to maximize the use of each adsorbent and to minimize the adsorber size [9].

One application for a pressure swing adsorption (PSA) process using a layered bed is air purification. Rege et al. [10] used a 1-bed, 4-step stripping PSA system to remove $\mathrm{H}_{2} \mathrm{O}$ and $\mathrm{CO}_{2}$ from an air feed. The adsorbents used in this study were activated alumina and zeolite $13 \mathrm{X}$. It was shown that the $\mathrm{H}_{2} \mathrm{O}$ concentration is optimum when the bed consisted of $75 \%$ activated alumina. The lowest $\mathrm{CO}_{2}$ concentration occurred when the bed was $50 \%$ activated alumina. This showed that the activated alumina was needed for $\mathrm{H}_{2} \mathrm{O}$ removal while the zeolite $13 \mathrm{X}$ was needed for $\mathrm{CO}_{2}$ removal. Reynolds et al. [11] showed that air purification can be accomplished with a 2-bed 3-step PSA system utilizing deep vacuum without a light reflux step. The maximum $\mathrm{CO}_{2}$ removal occurred with a layering of $50 \%$ silica gel, $17 \%$ zeolite $13 \mathrm{X}$, and $33 \%$ zeolite $5 \mathrm{~A}$. With this layering, $100 \%$ of the $\mathrm{H}_{2} \mathrm{O}$ and $88.0 \%$ of the $\mathrm{CO}_{2}$ were removed for a $10 \mathrm{~L}$ column. However, both of these air purification studies allowed the system to come to a periodic state with a constant feed composition.

The new Crew Exploration Vehicle (CEV), Orion, will not operate at periodic conditions. Instead, the crew and the PSA system will experience real-time changes in the cabin concentrations for $\mathrm{H}_{2} \mathrm{O}$ and $\mathrm{CO}_{2}$. 
So, why is it important to create a real-time dynamic cabin model? First, to gain better understanding of the performance of the PSA-SBAR system under typical dynamic conditions experienced in the cabin for the most diverse scenarios. Second, to foster the design, development, and evaluation of better PSA-SBAR systems. The objectives of this study are to introduce a real-time dynamic cabin model incorporating a PSASBAR system to simulate $\mathrm{H}_{2} \mathrm{O}$ and $\mathrm{CO}_{2}$ conditions inside a space craft cabin, validate the dynamic cabin model by showing how it agrees with a long-time steady state model, show simulations that display the effect of the feed flow rate, and cabin and column volumes on the removal of $\mathrm{H}_{2} \mathrm{O}$ and $\mathrm{CO}_{2}$ generated from a 4-person crew with a given metabolic production schedule during a 4-day period, and to show the effect on the removal of $\mathrm{H}_{2} \mathrm{O}$ and $\mathrm{CO}_{2}$ due to the amount of silica gel in the PSA column for a 6-person crew on a 3-day mission from earth to the international space station (ISS).

\section{PSA PROCESS DESCRIPTION}

The 2-bed 3-step stripping PSA cycle depicted in Figure 1 includes the following cycle steps: feed (F) at just above atmospheric pressure $\left(\mathrm{P}_{\mathrm{H}}\right)$, countercurrent depressurization (CnD), or evacuation, from $P_{H}$ to a lower pressure $\left(P_{L}\right)$, and feed pressurization $(F P)$ from $P_{L}$ to $P_{H}$. While one bed undergoes the FP and $F$ steps, the other bed undergoes the $\mathrm{CnD}$ step. The heavy products $\left(\mathrm{H}_{2} \mathrm{O}\right.$ and $\left.\mathrm{CO}_{2}\right)$ are removed from the system during the $\mathrm{CnD}$ step, whereas the light product (mainly $\mathrm{N}_{2}$ and $\mathrm{O}_{2}$ ) is recovered during the $\mathrm{F}$ step.

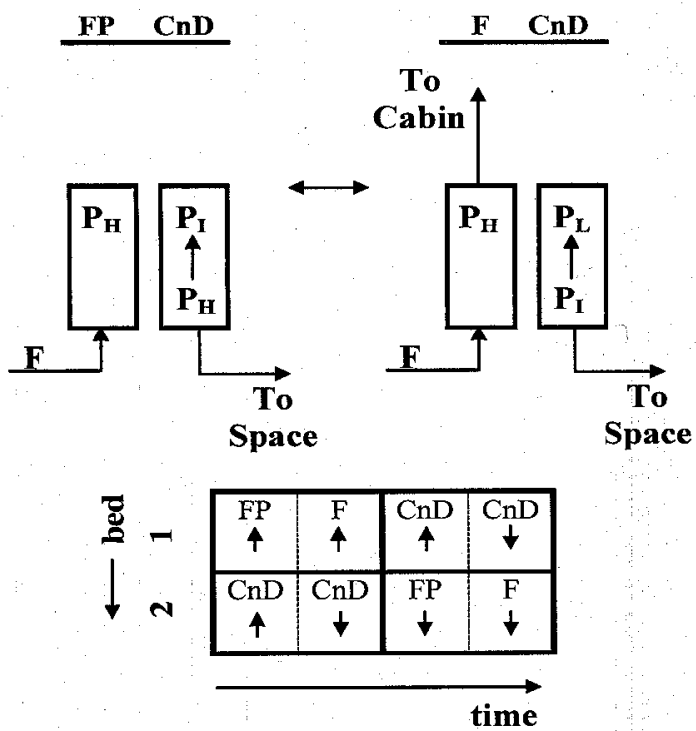

Figure 1. Schematic of the 2-bed 3-step stripping PSA cycle used in the parametric study with a layered bed. $F=$ feed; $\mathrm{CnD}=$ countercurrent depressurization; $F P=$ feed pressurization; $P_{L}=$ low pressure; $P_{H}=$ high pressure; $P_{1}=$ intermediate pressure.

Each bed consists of three adsorbent layers silica gel, zeolite $13 \mathrm{X}$, and zeolite $5 \mathrm{~A}$. The silica gel encompassed the first $50 \%$ of the bed from the feed end, the next $17 \%$ of the column was zeolite $13 \mathrm{X}$, and the final $33 \%$ of the column was zeolite $5 \mathrm{~A}$. The silica gel removed the bulk amount of water, the zeolite $13 \mathrm{X}$ was used to remove the remaining water and the bulk amount of carbon dioxide, and the zeolite $5 \mathrm{~A}$ was utilized for trace carbon dioxide removal.

The periodic state process performance of this PSA cycle is judged by the $\mathrm{H}_{2} \mathrm{O}$ and $\mathrm{CO}_{2}$ removal. The $\mathrm{H}_{2} \mathrm{O}$ or $\mathrm{CO}_{2}$ removal is defined as the amount of $\mathrm{H}_{2} \mathrm{O}$ or $\mathrm{CO}_{2}$ removed in the $\mathrm{CnD}$ step divided by the amount of $\mathrm{H}_{2} \mathrm{O}$ or $\mathrm{CO}_{2}$ fed to the column in the $\mathrm{F}$ and FP steps.

\section{MATHEMATICAL MODEL}

The assumptions and equations used by Reynolds et al. [11] in their rigorous multilayer PSA simulator are the same utilized in this study. However, some modifications were necessary to accommodate the extension to a cabin model. A schematic of the cabin model is shown in Figure 2. After each second the model calculates new amounts, in moles, of $\mathrm{H}_{2} \mathrm{O}$ and $\mathrm{CO}_{2}$ present in the cabin assuming perfect mixing of the moles coming from the PSA column into the cabin.

$n_{i, j}=n_{i, j-1}-n_{i, f e d}+n_{i, e f f l u e n t}+N_{\text {astronaut }} \cdot n_{i, \text { astronaut }}$

where $n_{i, j}$ is the new molar amount of component $\mathrm{i}$, $n_{i, j-1}$ is the previous molar amount of component $i$, $n_{i, f e d}$ is the molar amount of component i fed to the PSA system since the last update, $n_{i, \text { effuent }}$ is the molar amount of component $i$ returned to the cabin in the effluent from the PSA system since the last update, $N_{\text {astronout }}$ is the number of astronauts on-board the Orion, and $n_{i, \text { astronaut }}$ is the molar amount of component $\mathrm{i}$ produced by each astronaut based on the metabolic production of $\mathrm{H}_{2} \mathrm{O}$ and $\mathrm{CO}_{2}$ during the activity that the astronaut is currently undergoing. These molar amounts are then converted to partial pressures using the ideal gas law. The partial pressure of oxygen $\left(\mathrm{O}_{2}\right)$ is held constant at its atmospheric partial pressure, while the amount of nitrogen $\left(\mathrm{N}_{2}\right)$ added to the cabin is adjusted to ensure that the cabin pressure remains at the set pressure. Then, the molar fraction is calculated by

$y_{i}=\frac{n_{i, j}}{n_{T, j}}$

The total number of moles $\left(n_{T, j}\right)$ is calculated by summing the number of moles of all four components $\left(\mathrm{H}_{2} \mathrm{O}, \mathrm{CO}_{2}, \mathrm{O}_{2}\right.$ and $\left.\mathrm{N}_{2}\right)$. Finally, these new concentrations are used as the molar fractions of the feed to the column.

\section{RESULTS AND DISCUSSION}

The cabin model was first validated against a steady state model that was based only on the total flow, the fraction of time that one of the columns was undergoing the $F$ step, the metabolic rate of the 
astronauts, and the removal efficiency of the column. Figure 3 shows typical metabolic production rates during periods of rest, normal activity, exercise and normal activity for $\mathrm{H}_{2} \mathrm{O}$ and $\mathrm{CO}_{2}$ over a $24 \mathrm{hr}$ period. The schedule is repeated for each day during a mission. As can be seen in the figure, there are two distinct regions of exercise. The first region is a period of aerobic

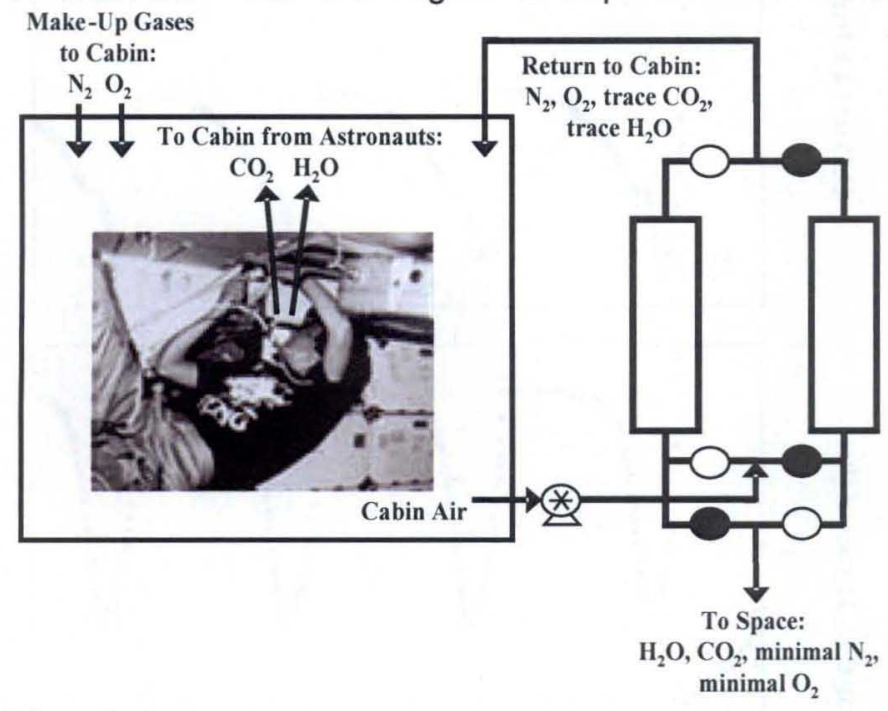

Figure 2. Schematic of the real-time dynamic cabin model used in the PSA-SBAR air purification study.

exercise, while the second region is a period of strength training. The PSA-SBAR system was in the feed step for 420 seconds out of a half cycle of 480 seconds, thus the fraction fed was 0.875 . For $10 \mathrm{~L}$ columns in the PSA-SBAR system, the dynamic cabin model had average removal efficiencies of $100 \%$ for $\mathrm{H}_{2} \mathrm{O}$ throughout the entire run and $83.0 \%, 82.9 \%, 79.6 \%$, $77.6 \%$ and $79.4 \%$ for $\mathrm{CO}_{2}$ during periods of rest, normal activity, aerobic exercise, strength exercise and normal activity, respectively. As shown in Figure 4, the cabin model was able to predict the steady state model values for $\mathrm{H}_{2} \mathrm{O}$ and $\mathrm{CO}_{2}$ for long periods of steady metabolic production. It also showed similar trends for the exercise periods, where there were quick changes in production rates.

Since the cabin model was validated against steady state predictions, a study was conducted to display the effect of the feed flow rate, and cabin and column volumes on the removal of $\mathrm{H}_{2} \mathrm{O}$ and $\mathrm{CO}_{2}$ generated from a 4-person crew with a given metabolic production schedule for a 4-day mission. The base case bed characteristics and operating parameters are shown in Table 1. The high pressure is set at atmospheric pressure, and the system is run with a high-to-low pressure ratio of 1,000 . The crew size, initial feed composition, feed flow rate, feed and ambient temperatures, and overall heat transfer coefficient were provided by NASA. The cycle step times are similar to those used in a previous study [11], and the mass transfer coefficient for $\mathrm{H}_{2} \mathrm{O}$ on silica gel was $0.002 \mathrm{~s}^{-1}$.

The effects of flow rate $(Q)$, cabin volume (Vcab), and column volume (Vcol) on cabin $\mathrm{H}_{2} \mathrm{O}$ and $\mathrm{CO}_{2}$ concentrations (Figure 5) and PSA removal efficiencies (Figure 6) are illustrated with a 4-day mission for a 4-person crew with a $\mathrm{H}_{2} \mathrm{O}$ and $\mathrm{CO}_{2}$ metabolic production schedule shown in Figure 3 . The bold and thin lines correspond to $\mathrm{H}_{2} \mathrm{O}$ and $\mathrm{CO}_{2}$, respectively. The dashed lines indicate the desired bounds (6 and 17.5 torr) for the $\mathrm{H}_{2} \mathrm{O}$ cabin concentration. These bounds are set to eliminate any harm to the astronauts. If the $\mathrm{H}_{2} \mathrm{O}$

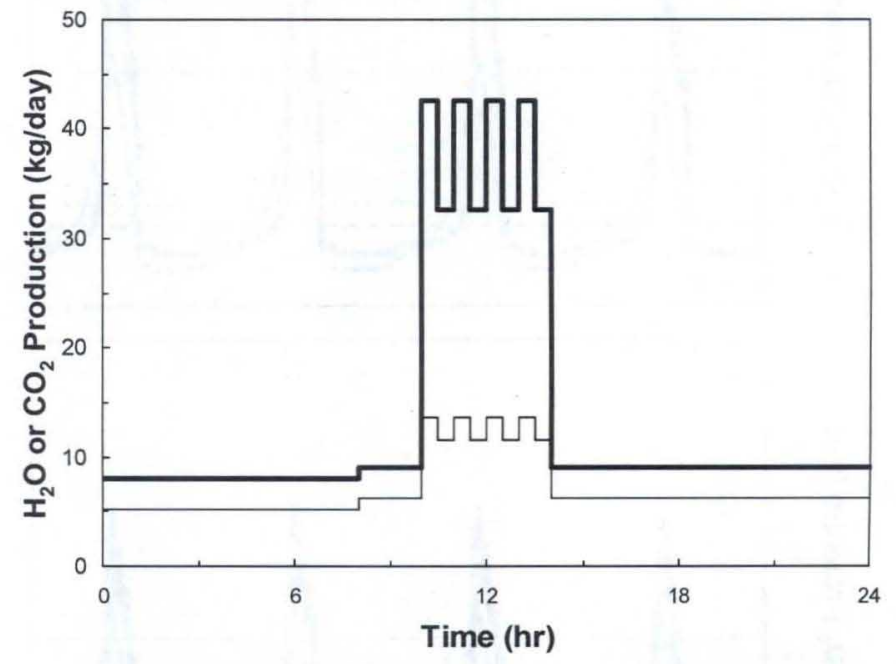

Figure 3. Typical metabolic production rates during periods of rest, normal activity, exercise and normal activity over a $24 \mathrm{hr}$ period for a 4person crew. Line styles: bold $-\mathrm{H}_{2} \mathrm{O}$; thin $-\mathrm{CO}_{2}$.

Table 1. Bed characteristics and operating parameters utilized in the 4-person crew PSA-SBAR air purification study.

$\begin{array}{rl}\text { Bed Length }(\mathrm{L}) & 0.244 \mathrm{~m} \\ \text { Bed Radius }\left(\mathrm{r}_{\mathrm{b}}\right) & 0.081 \mathrm{~m} \\ \text { Cabin Volume }\left(\mathrm{V}_{\text {cab }}\right) & 11 \mathrm{~m}^{3} \\ \text { High Pressure }\left(\mathrm{PH}_{\mathrm{H}}\right) & 101.325 \mathrm{kPa} \\ \text { Low Pressure }\left(\mathrm{P}_{\mathrm{L}}\right) & 0.101325 \mathrm{kPa} \\ \text { Crew Size } & 4 \\ \text { Initial Feed Mole Fraction: } \mathrm{H}_{2} \mathrm{O}, \mathrm{CO}_{2}, & 0.0125,0.0021 \\ \mathrm{O}_{2}, \mathrm{~N}_{2} & 0.2083,0.7771 \\ \text { Feed Flow Rate }\left(\mathrm{Q}_{\mathrm{F}}\right) & 700.00 \mathrm{SLPM} \\ \text { Feed Temperature }\left(\mathrm{T}_{\mathrm{F}}\right) & 291.48 \mathrm{~K} \\ \text { Ambient Temperature }\left(\mathrm{T}_{\mathrm{O}}\right) & 291.48 \mathrm{~K} \\ \text { Overall Heat Transfer Coefficient }(\mathrm{h}) & 5.68 \times 10^{-4} \mathrm{~kJ} / \mathrm{m}^{2} \mathrm{~s} \mathrm{~K} \\ \text { Step Times }\left(\mathrm{t}_{\mathrm{s}}\right): \mathrm{F}, \mathrm{CnD}, \mathrm{FP} & 420,480,60 \mathrm{~s}\end{array}$

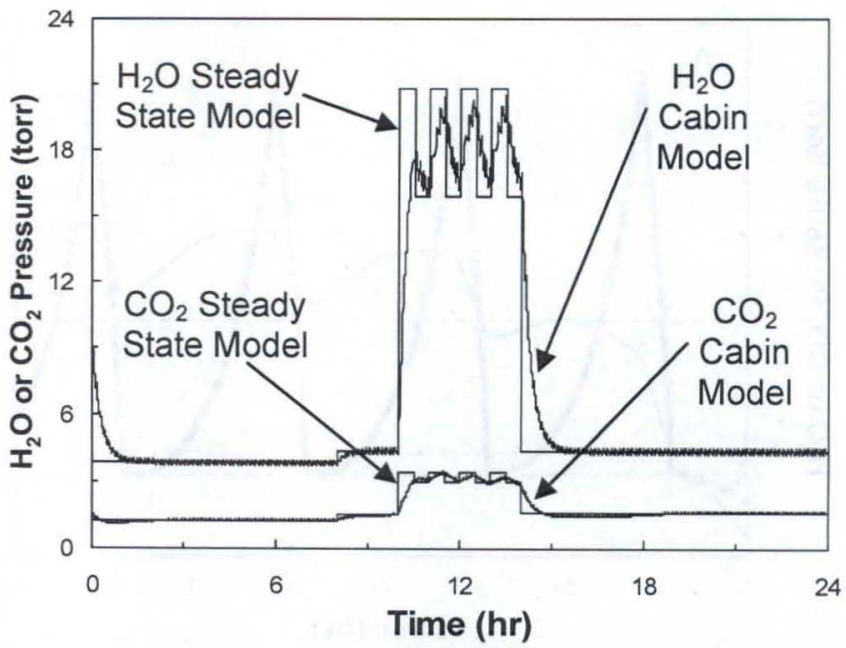

Figure 4. Validation run for the dynamic cabin model utilizing $10 \mathrm{~L}$ columns for the PSA-SBAR system. 

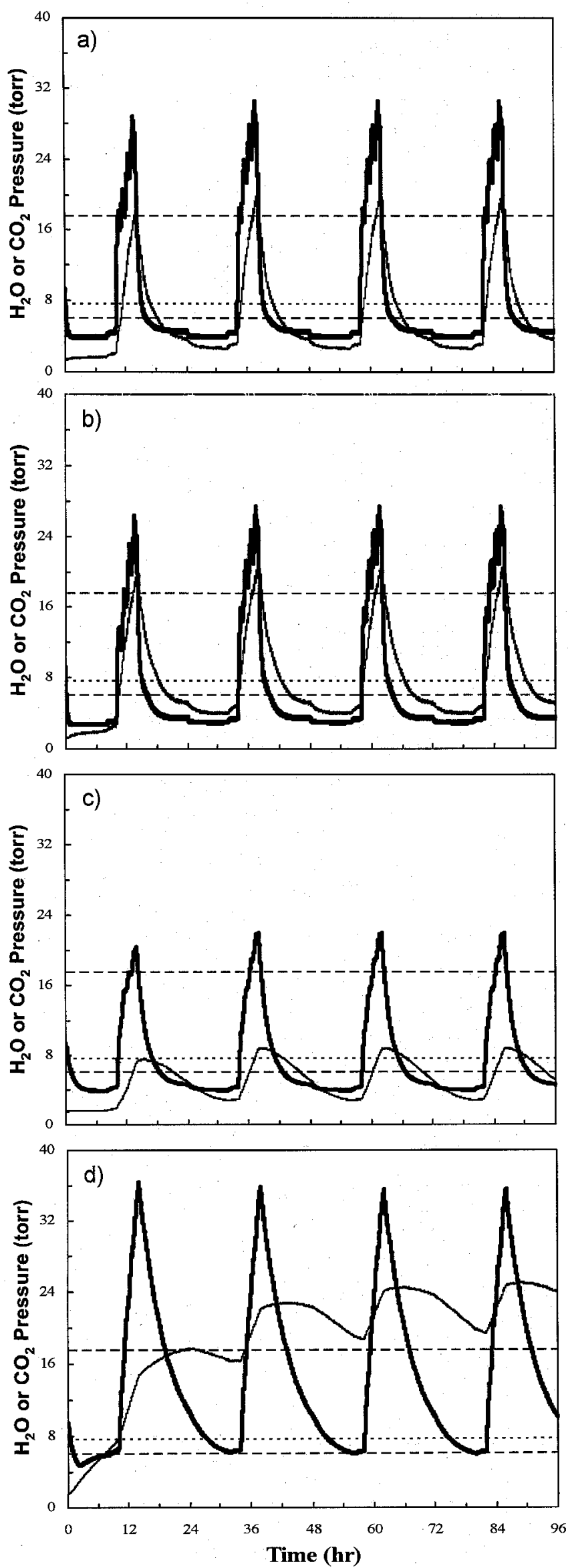

Figure 5. $\mathrm{H}_{2} \mathrm{O}$ and $\mathrm{CO}_{2}$ cabin concentrations from simulations of the dynamic cabin model for a) base case, b) effect of flow rate $\left(Q_{F}=1000\right.$ SLPM), c) effect of cabin volume $\left(V_{c a b}=44 \mathrm{~m}^{3}\right)$ and d) effect of column volume $\left(V_{c o l}=2.5 \mathrm{~L}\right.$ ). Line styles: bold $-\mathrm{H}_{2} \mathrm{O}$; thin $-\mathrm{CO}_{2}$; dashed $-\mathrm{H}_{2} \mathrm{O}$ bounds; dotted $-\mathrm{CO}_{2}$ upper bound.
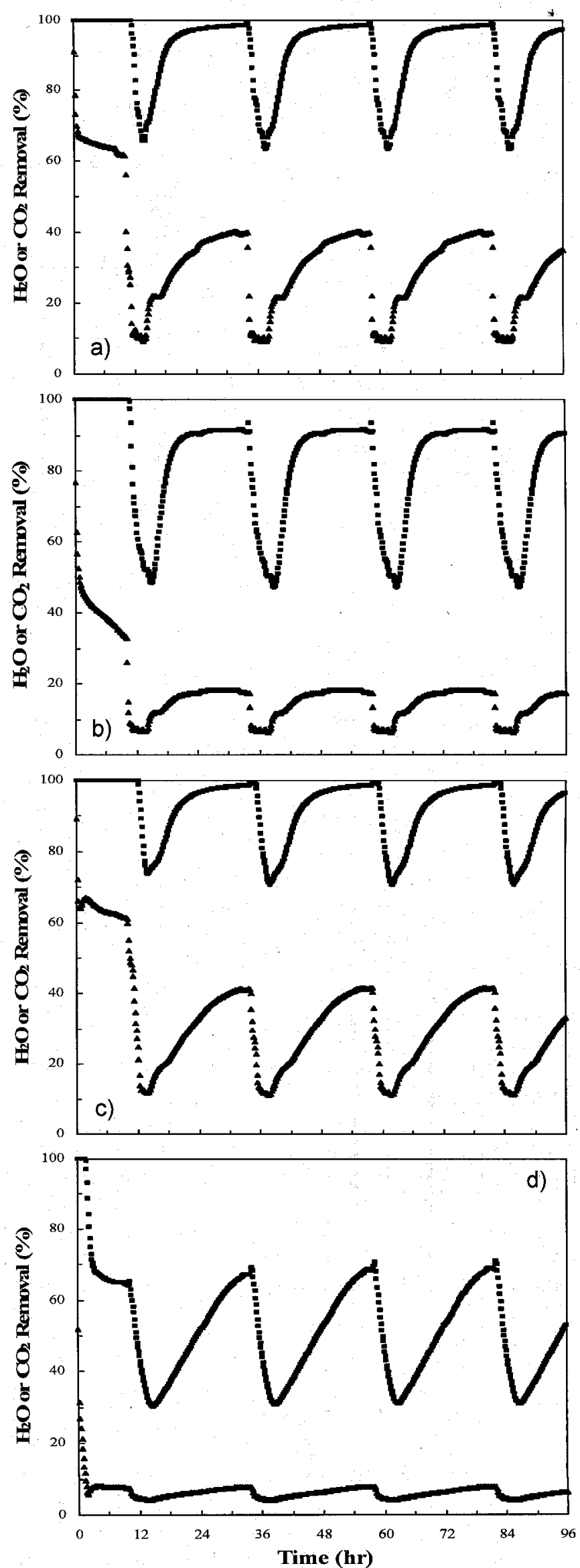

Figure 6. $\mathrm{H}_{2} \mathrm{O}$ and $\mathrm{CO}_{2}$ removal efficiencies from simulations of the dynamic cabin model for a) base case, b) effect of flow rate $\left(Q_{F}=1000\right.$ SLPM), c) effect of cabin volume $\left(V_{c a b}=44 \mathrm{~m}^{3}\right)$ and d) effect of column volume $\left(\mathrm{V}_{\text {col }}=2.5 \mathrm{~L}\right)$. Symbols: squares $-\mathrm{H}_{2} \mathrm{O}$; triangles $-\mathrm{CO}_{2}$. 
concentration goes below the lower bound, the astronauts' skin will begin to crack. If the upper bound is exceeded, $\mathrm{H}_{2} \mathrm{O}$ will begin to condense in the cabin. The dotted line indicates the safe upper bound (7.6 torr) for the $\mathrm{CO}_{2}$ cabin concentration. If this bound is exceeded for an extended amount of time, it would be harmful to the astronauts.

Figure 5(a) shows the base case condition. It can be seen that during periods of rest and normal activity there was too little $\mathrm{H}_{2} \mathrm{O}$. At the same time the $\mathrm{CO}_{2}$ was well below its bound. During these periods, the column was removing too much water and drying the cabin out. This can be avoided by slowing the feed flow rate down. However, during exercise periods the upper bounds for both $\mathrm{H}_{2} \mathrm{O}$ and $\mathrm{CO}_{2}$ were exceeded. As shown in Figure 6(a), the removal efficiency for both $\mathrm{H}_{2} \mathrm{O}$ and $\mathrm{CO}_{2}$ fell shortly after the exercise period began. The $\mathrm{H}_{2} \mathrm{O}$ removal efficiency falling meant that the $\mathrm{H}_{2} \mathrm{O}$ penetrated through the zeolite layers and returned to the cabin. Since the $\mathrm{CO}_{2}$ was removed only by the zeolite layers, its removal efficiency fell as the $\mathrm{H}_{2} \mathrm{O}$ was preferentially adsorbed by the zeolites. However, an interesting observation of Figure 5(a) was that the $\mathrm{H}_{2} \mathrm{O}$ and $\mathrm{CO}_{2}$ concentrations returned to the pre-exercise level within a few hours.

Figure 5(b) shows the $\mathrm{H}_{2} \mathrm{O}$ and $\mathrm{CO}_{2}$ concentrations for the effect of increasing $Q$ to 1000 SLPM. Higher flow rates should lead to lower $\mathrm{H}_{2} \mathrm{O}$ and $\mathrm{CO}_{2}$ cabin concentrations. The concentrations of $\mathrm{H}_{2} \mathrm{O}$ and $\mathrm{CO}_{2}$ in the cabin were only slightly lower than those from the base case. A large decrease in the cabin concentrations was not observed due to the lower removal efficiencies of the PSA unit as shown in Figure $6(b)$.

Figure 5(c) shows the effect of increasing the $V_{\text {cab }}$ to $44 \mathrm{~m}^{3}$. The $\mathrm{H}_{2} \mathrm{O}$ and $\mathrm{CO}_{2}$ cabin concentrations were reduced, even though the removal efficiencies were similar to the base case. The concentrations, however, still exceeded the upper bounds. But, this did not happen until much later in the exercise period. The larger cabin led to a slower response, which dampened the large variations observed in Figure 5(a).

Table 2. Bed characteristics and operating parameters utilized in the 6-person crew PSA-SBAR air purification study.

\begin{tabular}{r|l} 
Bed Length $(\mathrm{L})$ & $0.244 \mathrm{~m}$ \\
Bed Radius $\left(\mathrm{r}_{\mathrm{b}}\right)$ & $0.081 \mathrm{~m}$ \\
High Pressure $\left(\mathrm{P}_{\mathrm{H}}\right)$ & $101.325 \mathrm{kPa}$ \\
Low Pressure $\left(\mathrm{P}_{\mathrm{L}}\right)$ & $0.101325 \mathrm{kPa}$ \\
Crew Size & 6 \\
Fraction: $\mathrm{H}_{2} \mathrm{O}, \mathrm{CO}_{2}$, & $0.0125,0.0033$, \\
$\mathrm{O}_{2}, \mathrm{~N}_{2}$ & $0.2083,0.7759$ \\
Feed Flow Rate $\left(\mathrm{Q}_{\mathrm{F}}\right)$ & $849.51 \mathrm{SLPM}$ \\
eed Temperature $\left(\mathrm{T}_{\mathrm{F}}\right)$ & $294.26 \mathrm{~K}$ \\
ent Temperature $\left(\mathrm{T}_{\mathrm{o}}\right)$ & $294.26 \mathrm{~K}$ \\
ansfer Coefficient $(\mathrm{h})$ & $5.68 \times 10^{-4} \mathrm{~kJ} / \mathrm{m}^{2} \mathrm{~s} \cdot \mathrm{K}$ \\
Times $\left(\mathrm{t}_{\mathrm{s}}\right)$ : F,CnD, $\mathrm{FP}$ & $420,480,60 \mathrm{~s}$ \\
\hline
\end{tabular}

Figure 5(d) shows the effect of decreasing $V_{\text {col }}$ to $2.5 \mathrm{~L}$. The cabin concentrations were dramatically higher than that observed for the base case. In fact, the $\mathrm{CO}_{2}$ concentration never came to a periodic state. The smaller column led to lower removal, efficiencies resulting in higher $\mathrm{H}_{2} \mathrm{O}$ and $\mathrm{CO}_{2}$ cabin concentrations.

The second study performed on this system consisted of a 6-person crew undertaking ground operations and a 3-day mission to dock the Orion with the ISS. Ground operations consisted of a 6 hour period of time prior to launch. Throughout the ground operations the PSA-SBAR system was run at atmospheric conditions with one system undergoing the $F$ step and the other system undergoing a purge step that consisted of $\mathrm{N}_{2}$ flowing in a countercurrent direction to remove $\mathrm{H}_{2} \mathrm{O}$ and $\mathrm{CO}_{2}$ from the adsorbent layers. After ground operations, there was essentially no $\mathrm{H}_{2} \mathrm{O}$ or $\mathrm{CO}_{2}$ on the adsorbents due to the $\mathrm{N}_{2}$ purge.

Table 2 shows the conditions used for the 5 simulations run in this study. The initial feed mole fraction is the concentration of the components in the cabin at the start of ground operations. The mass transfer coefficient for $\mathrm{H}_{2} \mathrm{O}$ on silica gel was $0.029 \mathrm{~s}^{-1}$. This number was used as a conservative estimate of results from recent experiments not shown here. The metabolic production schedule is shown for one day in Figure 7. Again, this schedule is repeated every day during the mission. Since there are 6 crew members and a short mission, no exercise is required.

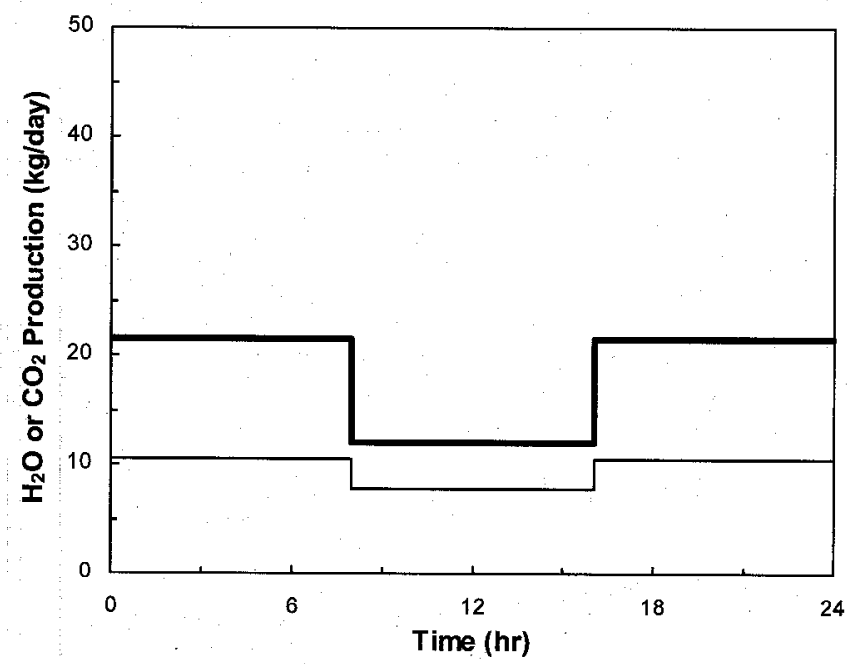

Figure 7. Typical metabolic production rates during periods of normal activity, rest and normal activity over a $24 \mathrm{hr}$ period for a 6-person crew. Line styles: bold $-\mathrm{H}_{2} \mathrm{O}$; thin $-\mathrm{CO}_{2}$.

Figure 8 shows the $\mathrm{H}_{2} \mathrm{O}$ and $\mathrm{CO}_{2}$ cabin concentrations for ground operations followed by a 3day mission to the ISS, while Figure 9 shows the removal efficiencies of $\mathrm{H}_{2} \mathrm{O}$ and $\mathrm{CO}_{2}$ and the loss of $\mathrm{O}_{2}$ and $\mathrm{N}_{2}$ to space for only the 3-day mission. The first 6 hours of Figure 8 correspond to the ground operations. It can be seen that the $\mathrm{H}_{2} \mathrm{O}$ and $\mathrm{CO}_{2}$ came to a periodic state in the cabin and that the levels in the cabin were well within the bounds for each component. The $\mathrm{H}_{2} \mathrm{O}$ concentration in the cabin fell below the lower bound during the rest period for each of the 3 days. This was due to the high flow rate being held constant throughout the entire run. To keep the $\mathrm{H}_{2} \mathrm{O}$ level above the lower bound, the flow rate can be reduced during periods of 
rest. However, the $\mathrm{CO}_{2}$ concentration went above its safe upper limit during the second day of normal activity. This was due to $\mathrm{H}_{2} \mathrm{O}$ penetrating into the zeolite layers. Water preferentially adsorbed to the zeolite, thus $\mathrm{CO}_{2}$ was not be able to adsorb and be removed from the feed stream. This can be seen in Figure 9 as the $\mathrm{CO}_{2}$ removal efficiency continuously declined until about 40 hours into the 3-day mission. One last observation from Figure 8 is that the $\mathrm{H}_{2} \mathrm{O}$ concentration began to increase in the cabin after approximately 58 hours of operation (52 hours into the mission). This was due to $\mathrm{H}_{2} \mathrm{O}$ breaking through the column and returning to the cabin in the PSA effluent stream. This observation corresponded with the drop in the removal efficiency of $\mathrm{H}_{2} \mathrm{O}$ shown in Figure 9.

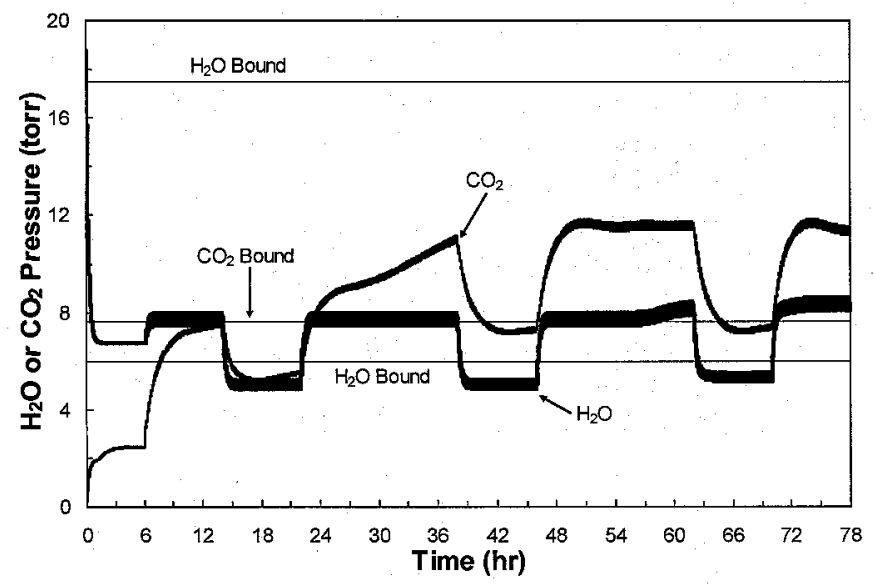

Figure 8. $\mathrm{H}_{2} \mathrm{O}$ and $\mathrm{CO}_{2}$ cabin concentrations for ground operations and a 3-day mission to the ISS for a system containing $50 \%$ silica gel.

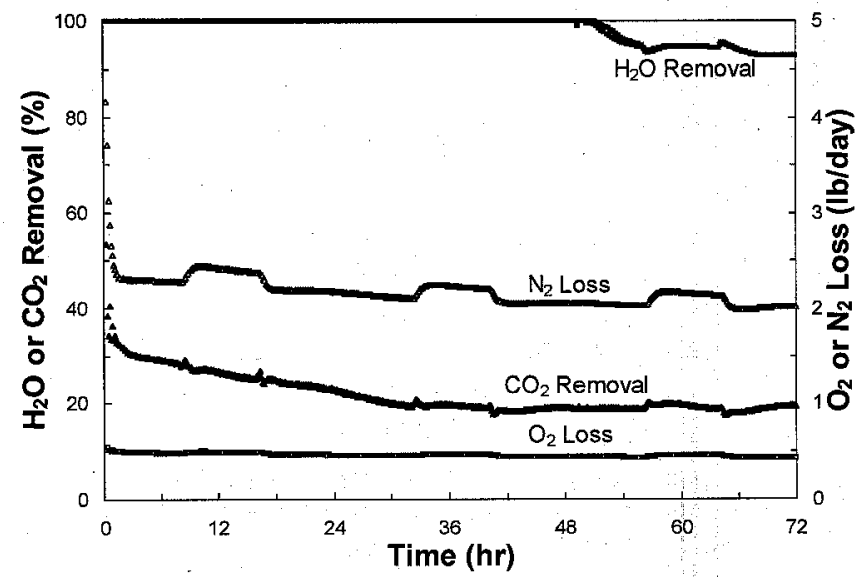

Figure 9. $\mathrm{H}_{2} \mathrm{O}$ and $\mathrm{CO}_{2}$ removal efficiencies and $\mathrm{O}_{2}$ and $\mathrm{N}_{2}$ losses for a 3-day mission to the ISS for a system containing $50 \%$ silica gel. Symbols: squares $-\mathrm{H}_{2} \mathrm{O}$ removal efficiency; triangles $-\mathrm{CO}_{2}$ removal efficiency; empty squares $-\mathrm{O}_{2}$ loss; empty triangles $-\mathrm{N}_{2}$ loss.

The effect of the amount of silica gel in the PSASBAR column on the $\mathrm{H}_{2} \mathrm{O}$ and $\mathrm{CO}_{2}$ cabin concentrations were difficult to see in a graph similar to Figure 8. There were only slight differences between the cabin concentrations achieved with $35 \%$ and $55 \%$ silica gel. However, the differences can be seen with graphs similar to Figure 9. Thus, Figures 10 and 11 show the effect of the amount of silica gel in the PSA-SBAR column on the removal efficiencies of $\mathrm{H}_{2} \mathrm{O}$ and $\mathrm{CO}_{2}$.

As the silica gel percentage increased in the column, the $\mathrm{H}_{2} \mathrm{O}$ removal efficiency remained higher throughout the run as shown in Figure 10 . Since the silica gel was used as the bulk $\mathrm{H}_{2} \mathrm{O}$ remover, more silica gel in the column led to more $\mathrm{H}_{2} \mathrm{O}$ being removed. This, in turn, meant that less $\mathrm{H}_{2} \mathrm{O}$ needed to be adsorbed by the zeolite layers. Thus, breakthrough of the $\mathrm{H}_{2} \mathrm{O}$ occurred later in the run for the columns containing more silica gel. Therefore, the $\mathrm{H}_{2} \mathrm{O}$ concentration in the cabin was slightly lower for the columns containing more silica gel.

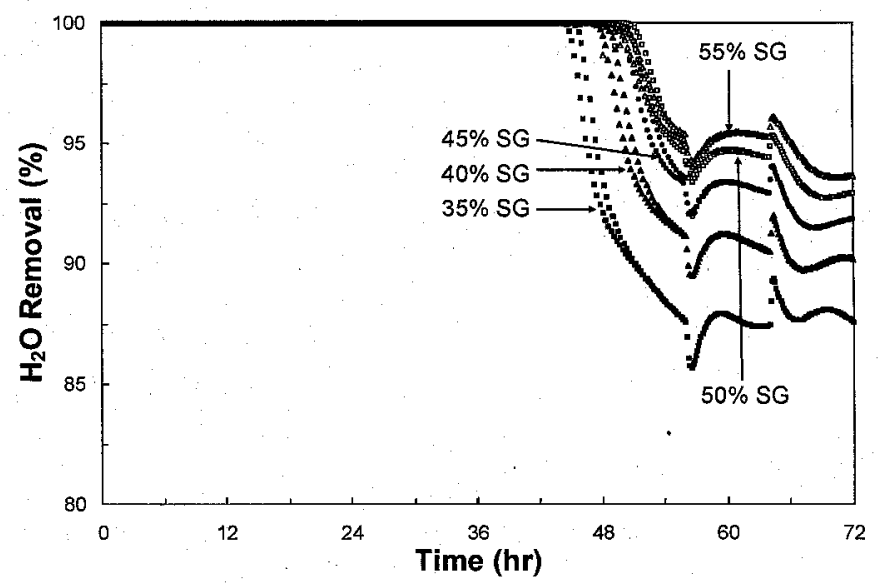

Figure 10. $\mathrm{H}_{2} \mathrm{O}$ removal efficiency for a 3-day mission for the CEV to dock with the ISS. Symbols: squares $-35 \%$ silica gel; triangles $-40 \%$ silica gel; circles - $45 \%$ silica gel; empty squares $-50 \%$ silica gel; empty triangles $-55 \%$ silica gel.

Figure 11 shows the $\mathrm{CO}_{2}$ removal efficiency throughout the 3-day mission as a function of the silica gel percentage. The silica gel had an opposite effect on the $\mathrm{CO}_{2}$ as it did on the $\mathrm{H}_{2} \mathrm{O}$. For $\mathrm{CO}_{2}$, the removal efficiency decreased as the silica gel percentage increased. This was caused by the fact that as the silica gel percentage increased the percentage of zeolite $13 \mathrm{X}$ decreased. Since the $\mathrm{CO}_{2}$ was removed only by the zeolite layers, the capacity to remove the $\mathrm{CO}_{2}$ from the feed stream was decreased as the zeolite $13 \mathrm{X}$ amount was decreased. Therefore, the cabin concentration of $\mathrm{CO}_{2}$ increased as the silica gel percentage increased.

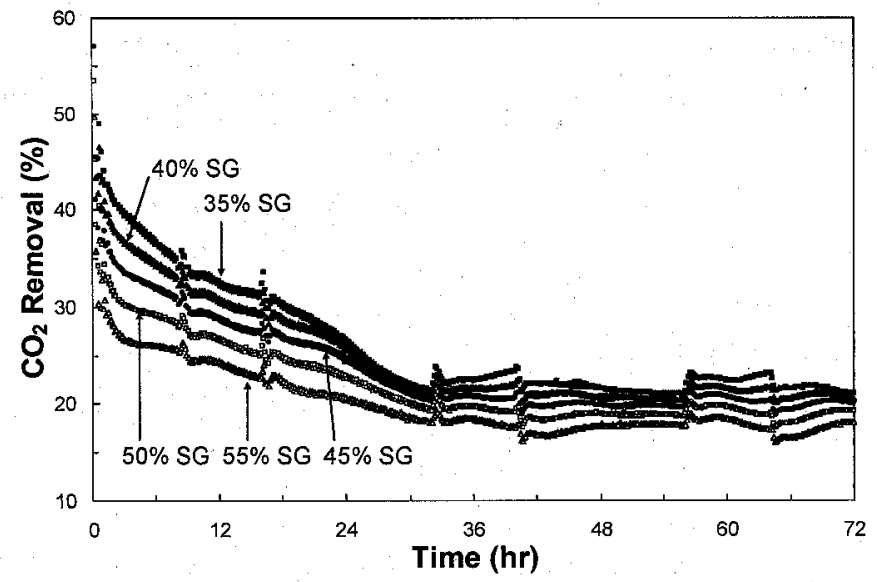

Figure 11. $\mathrm{CO}_{2}$ removal efficiency for a 3-day mission for the CEV to dock with the ISS. Symbols: squares $-35 \%$ silica gel; triangles $-40 \%$ silica gel; circles - $45 \%$ silica gel; empty squares - $50 \%$ silica gel; empty triangles $-55 \%$ silica gel. 


\section{CONCLUSIONS}

A rigorous cabin model was developed to aid in the design and development for the SBAR system on the new CEV, Orion. This cabin model was able to update the cabin concentrations of $\mathrm{H}_{2} \mathrm{O}$ and $\mathrm{CO}_{2}$ every second throughout the run. It was validated against a steady state model that was based only on the total flow, the fraction of time that one of the columns was undergoing the $F$ step, the metabolic rate of the astronauts, and the removal efficiency of the column. The dynamic cabin model was able to predict the steady state model values for $\mathrm{H}_{2} \mathrm{O}$ and $\mathrm{CO}_{2}$ for long periods of steady metabolic production. It also shows similar trends for the exercise periods, where there are quick changes in production rates.

Once validated, the dynamic cabin model was used to illustrate the effect of flow rate, cabin volume and column volume on the cabin concentrations of $\mathrm{H}_{2} \mathrm{O}$ and $\mathrm{CO}_{2}$ for a 4-person crew over a 4-day period. Increasing the flow rate led to slightly lower cabin concentrations of $\mathrm{H}_{2} \mathrm{O}$ and $\mathrm{CO}_{2}$ since more of these components are able to interact with the adsorbent. The expected decrease in the cabin concentrations was not observed as the removal efficiency for both $\mathrm{H}_{2} \mathrm{O}$ and $\mathrm{CO}_{2}$ was much lower than the base case.

An increase in the cabin volume caused a reduction in the $\mathrm{H}_{2} \mathrm{O}$ and $\mathrm{CO}_{2}$ cabin concentrations, even though the removal efficiencies were similar to the base case. The larger cabin led to a slower response, which dampened the large variations observed in the base case. A smaller column adsorbed less $\mathrm{H}_{2} \mathrm{O}$ and $\mathrm{CO}_{2}$ than the base case which resulted in dramatically larger cabin concentration than the base case. In fact, the $\mathrm{CO}_{2}$ concentration never came to a periodic state. The smaller column led to lower removal efficiencies resulting in higher $\mathrm{H}_{2} \mathrm{O}$ and $\mathrm{CO}_{2}$ cabin concentrations.

Finally, the cabin model was used to observe the effect of the silica gel percentage in the column on the concentrations of $\mathrm{H}_{2} \mathrm{O}$ and $\mathrm{CO}_{2}$. As the silica gel percentage increased in the column, the $\mathrm{H}_{2} \mathrm{O}$ removal efficiency remained higher throughout the run. Thus, breakthrough of the $\mathrm{H}_{2} \mathrm{O}$ occurred later in the run for the columns containing more silica gel. Therefore, the $\mathrm{H}_{2} \mathrm{O}$ concentration in the cabin was slightly lower for the columns containing more silica gel. The silica gel, though, had an opposite effect on the $\mathrm{CO}_{2}$ as it did on the $\mathrm{H}_{2} \mathrm{O}$. For $\mathrm{CO}_{2}$, the removal efficiency decreased as the silica gel percentage increased. This was caused by the fact that as the silica gel percentage increased the percentage of zeolite $13 \mathrm{X}$ was decreased. Thus, the capacity to remove the $\mathrm{CO}_{2}$ from the feed stream was decreased as the zeolite $13 \mathrm{X}$ amount was decreased. Therefore, the cabin concentration of $\mathrm{CO}_{2}$ increased as the silica gel percentage increased.

\section{ACKNOWLEDGEMENTS}

Financial support for this work provided by the NASA MSFC was greatly appreciated.

\section{REFERENCES}

1. Ebner, A.D., and J.A. Ritter, "Equilibrium Theory Analysis of a Rectifying Pressure Swing Adsorption Process for Producing Pure Heavy Component," AlChE J., 48, 1679-1691 (2002).

2. Mclntyre, J.A., C.E. Holland, and J.A. Ritter, "High Enrichment and Recovery of Dilute Hydrocarbons by Dual Reflux Pressure Swing Adsorption," Ind. Eng. Chem. Res., 41, 3499-3504 (2002).

3. Daniel, K.D., and J.A. Ritter, "Equilibrium Theory Analysis of a Pressure Swing Adsorption Cycle Utilizing an Unfavorable Langmuir Isotherm. 1. Periodic Behavior," Ind. Eng. Chem. Res., 41, 36763687 (2002).

4. Liu, Y., J.A. Ritter, and B.K. Kaul, "Pressure Swing Adsorption Cycles for Improved Solvent Vapor Enrichment," AlChE J., 46, 540-551 (2000).

5. Liu, Y., C.E. Holland, and J.A. Ritter, "Solvent Vapor Recovery by Pressure Swing Adsorption. III. Comparison of Simulation with Experiment for the Butane-Activated Carbon System," Sep. Sci. Tech., 34, 1545-1576 (1999).

6. Ritter, J.A., Y. Liu, and D. Subramanian, "New Vacuum Swing Adsorption Cycles for Air Purification with the Feasibility of Complete Clean-Up," Ind. Eng. Chem. Res., 37, 1970-1976 (1998).

7. Liu, Y., and J.A. Ritter, "Evaluation of Model Approximations in Simulating Pressure Swing Adsorption-Solvent Vapor Recovery," Ind. Eng. Chem. Res., 36, 1767-1778 (1997).

8. Chlendi, M., and D. Tondeur, "Dynamic Behaviour of Layered Columns in Pressure Swing Adsorption," Gas. Sep. Purif., 9, 231-242 (1995).

9. Park, J.-H., J.-N. Kim, S.-H. Cho, J.-D. Kim, and R.T Yang, "Adsorber dynamics and optimal design of layered beds for multicomponent gas adsorption," Chem. Engng. Sci., 53, 3951-3963 (1998).

10. Rege, S.U., R.T. Yang, K. Qian, and M.A. Buzanowski, "Air-Prepurification by Pressure Swing Adsorption Using Single/Layered Beds. Chem. Eng. Sci., 56, 2745-2759 (2001).

11. Reynolds, S. P., A. D. Ebner, and J. A. Ritter, "Novel Layered Bed PSA Cycle for $\mathrm{CO} 2$ and $\mathrm{H} 2 \mathrm{O}$ Removal from Air Utilizing Deep Vacuum and No Light Reflux,"Sep. Sci. Tech., submitted (2007).

\section{CONTACT}

E-mail: ritter@engr.sc.edu 